\title{
RANCANG BANGUN SISTEM REKOMENDASI PEMILIHAN WEDDING ORGANIZER MENGGUNAKAN METODE SIMPLE ADDITIVE WEIGHTING
}

\author{
Yolanda Agusti Astri ${ }^{1}$, Novita Br.Ginting ${ }^{2}$, Dewi Primasari ${ }^{3}$ \\ 1,2,3 Universitas Ibn Khaldun; J1.KH.Sholeh Iskandar Bogor \\ Jurusan Teknik Informatika, Fakultas Teknik, Universitas Ibn Khaldun, Bogor \\ prayoga.yolanda06@gmail.com ${ }^{1}$
}

\begin{abstract}
Abstrak
Pernikahan merupakan suatu acara sakral yang diselenggarakan dengan persiapan yang sangat matang. Demi memaksimalkan waktu dan biaya, beberapa calon pengantin menggunakan jasa sebuah Wedding Organizer. Wedding Organizer merupakan suatu jasa yang memberikan pelayanan khusus secara pribadi yang bertujuan untuk membantu calon pengantin dan keluarga calon pengantin dari mulai perencanaan sampai tahap pelaksanaan. Untuk membantu calon pengantin melakukan pemilihan Wedding Organizer diperlukan perhitungan khusus untuk masing-masing alternatif dengan kriteria yang dimiliki. Maka dari itu diperlukan sistem rekomendasi yang dapat memberikan solusi pemilihan wedding organizer dengan metode perhitungan Simple Additive Weighting (SAW). Konsep dasar metode Simple Additive Weighting (SAW) adalah mencari penjumlahan terbobot dari rating kinerja pada setiap alternatif pada semua atribut Metode pengembangan sistem yang digunakan penenilitian ini adalah Waterfall, dimana terdapat beberapa proses yang berjalan secara berurutan yaitu Analysis, Design, Code, dan Test. Hasil penelitian ini adalah sebuah sistem rekomendasi pemilihan Wedding Organizer menggunakan metode Simple Additive Weighting (SAW) dengan perancangan sistem menggunakn model UML yang menghasilkan Use Case Diagram, Activity Diagram, Sequence Diagram, Class Diagram, Deployment Diagram, Design Database, dan Design Interface.
\end{abstract}

Kata kunci-Wedding Organizer, Simple Additive Weighting, Waterfall

\begin{abstract}
Marriage is a sacred event held with very mature preparation. In order to maximize time and cost, some brides use the services of a Wedding Organizer. Wedding Organizer is a service that provides special services in private that aims to help prospective brides and brides'families from planning to the implementation stage. To help the bride and groom make a selection of Wedding Organizer, special calculations are needed for each alternative with the criteria they have. Therefore, a recommendation system is needed that can provide a solution for choosing a wedding organizer using the Simple Additive Weighting (SAW) calculation method. The basic concept of the method of Simple Additive Weighting ( $S A W)$ is to find a weighted sum of performance ratings on each alternative on all attributes. The system development method used in this research is Waterfall, where there are several processes that run sequentially namely Analysis, Design, Code, and Test. The results of this study are a selection system for Wedding Organizer recommendations using the Simple Additive Weighting (SAW) method with system design using the UML model that produces Use Case Diagrams, Activity Diagrams, Sequence Diagrams, Class Diagrams, Deployment Diagrams, Database Design, and Interface Design.
\end{abstract}

Keywords- Wedding Organizer, Simple Additive Weighting, Waterfall

1. PENDAHULUAN
Pernikahan merupakan suatu acara sakral yang diselenggarakan dengan persiapan yang sangat matang. 
Mempersiapkan sebuah pesta pernikahaan tidak mudah, dibutuhkan waktu yang banyak untuk mencari segala kebutuhannya. Demi memaksimalkan waktu dan biaya, beberapa calon pengantin menggunakan jasa sebuah Wedding Organizer. Wedding Organizer merupakan suatu jasa yang memberikan pelayanan khusus secara pribadi yang bertujuan untuk membantu calon pengantin dan keluarga calon pengantin dari mulai perencanaan sampai tahap pelaksanaan. mengatur kelangsungan dari acara pernikahan tersebut.

Beberapa calon pengantin dihadapkan dengan kesulitan pada proses pemilihan Wedding Organizer yang sesuai dengan kebutuhan dan biaya yang ada, hal ini disebabkan karena kurangnya pengetahuan dan penelitian mengenai Wedding Organizer yang akan dipilih. Pada pemilihan Wedding Organizer terdapat faktor-faktor yang menjadi pertimbangan antara lain adalah budget atau biaya yang dimiliki oleh pengantin, kesesuaian konsep yang diinginkan, profesionalisme dari Wedding Organizer, pengalaman atau reputasi Wedding Organizer, serta kualitas yang dimiliki Wedding Organizer tersebut.

Untuk membantu calon pengantin melakukan pemilihan Wedding Organizer diperlukan perhitungan khusus untuk masing-masing alternatif dengan kriteria yang dimiliki. Maka dari itu diperlukan sistem rekomendasi yang dapat memberikan solusi pemilihan Wedding Organizer dengan metode pengambilan keputusan yang tepat.

Metode akan digunakan untuk menyelesaikan permasalahan dalam pengambilan keputusan pemilihan Wedding Organizer adalah Simple Additive Weighting (SAW). Metode SAW dikenal dengan istilah metode penjumlahan terbobot, konsep dasar metode Simple Additive Weighting (SAW) adalah mencari penjumlahan terbobot dari rating kinerja pada setiap alternatif pada semua atribut. Kemudian dilanjutkan dengan proses perangkingan yang akan menyeleksi alternatif terbaik dari sejumlah alternatif [1].

Beberapa penelitian mengenai sistem informasi rekomendasi dengan metode Simple Additive Weighting (SAW), seperti pada kasus pencari kerja terbaik, hasil dari penelitian tersebut yaitu dapat memberikan rekomendasi pencari kerja terbaik serta berhasil membantu pencari kerja untuk memberikan rekomendasi lowongan kerja yang sesuai dengan minat pencari kerja [2]. Meninjau pentingnya rekomendasi pemilihan Wedding Organizer agar tidak terjadi kesalahan saat proses pemilihan tersebut, Sehingga dalam penelitian ini akan mengangkat judul yaitu "RANCANG BANGUN SISTEM REKOMENDASI PEMILIHAN WEDDING ORGANIZER MENGGUNAKAN METODE SIMPLE ADDITIVE WEIGHTING (SAW)".

\section{METODE PENELITIAN}

Penelitian ini menggunakan metode pengembangan sistem waterfall. Model waterfall merupakan suatu proses pengembangan perangkat lunak secara berurutan, dimana kemajuan dipandang sebagai siklus mengalir melewati fase analisis, perancangan atau desain, implementasi (code) dan pengujian [3]. Tahapan-tahapan dalam model waterfall ditampilkan pada Gambar 1 berikut ini.

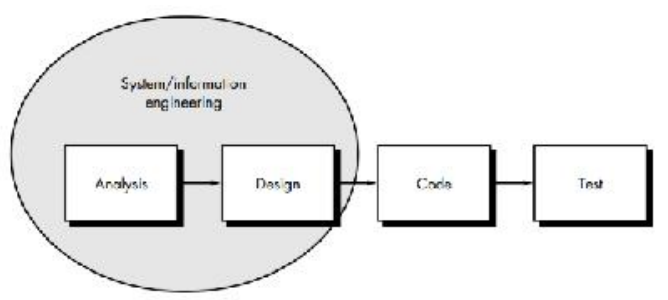

Gambar 1 Waterfall Model

\section{HASIL DAN PEMBAHASAN}

Mengacu pada metode pengembangan sistem waterfall maka dapat diterapkan pada penelitian ini sebagai bentuk penjabaran dari metode waterfall seperti gambar dibawah.

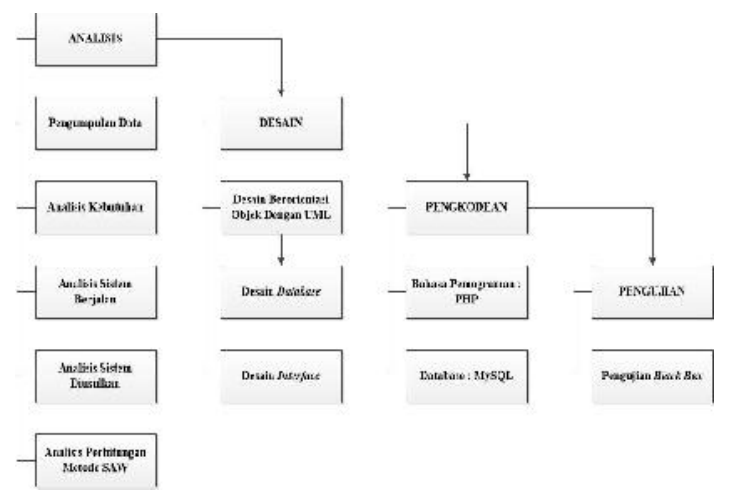


Gambar 2 Penjabaran Metode Waterfall.

1) Tahap Analisis (Requirements Definition)

2) Tahap Perancangan (System and Software Design)

3) Tahap Pengkodean (Implementasi and Unit Testing)

4) Tahap Pengujian (Integration and System Testing)

\subsection{Analisis}

Tahap ini merupakan tahap pengumpulan infromasi kebutuhan data untuk menspesifikasikan kebutuhan perangkat lunak agar mudah dipahami perangkat lunak apa yang dibutuhkan oleh user. Berikut merupakan tahapan dari analisis a) Pengumpulan Data

Metode pengumpulan data yang diterapkan pada penelitian ini meliputi dua cara yang diuraikan sebagai berikut:

1. Studi literatur dilakukan dengan membaca dan mempelajari buku yang berhubungan dengan analisis dan perancangan sistem. Selain itu juga membaca publikasi penelitian terkait dari berbagai sumber.

2. Observasi, kuesioner dan wawancara dengan responden (calon pengantin) mengenai rekomendasi pemilihan Wedding Organizer.

b) Analisis Kebutuhan

Dalam tahap ini terdapat beberapa langkah yang perlu dilakukan dalam pengembangan sistem pada penelitian ini, yaitu :

1. Analisis kebutuhan fungsional

Mendefinisikan hal-hal yang terkait dengan fungsi dan kegunaan sistem yang akan dibangun.

2. Analisis kebutuhan pengguna

Mendefinisikan pelaku atau aktor yang terlibat dalam sistem beserta kegiatan yang dapat dilakukan oleh aktor tersebut terhadap sistem. Pengguna pada sistem ini adalah calon pengantin yang membutuhkan rekomendasi mengenai pemilihan wedding organizer yang akan digunakan.

c) Analisis Sistem Yang Sedang Berjalan Analisis sistem yang sedang berjalan dilakukan untuk mengidentifikasi aliran informasi sistem yang berjalan dalam pemilihan wedding organizer. Sehingga akan dapat diperoleh rancangan alur baru yang akan diusulkan berdasarkan kebutuhan calon pengantin dalam rekomendasi pemilihan wedding organizer. Analisis sistem yang sedang berjalan, ditunjukan pada gambar berikut.

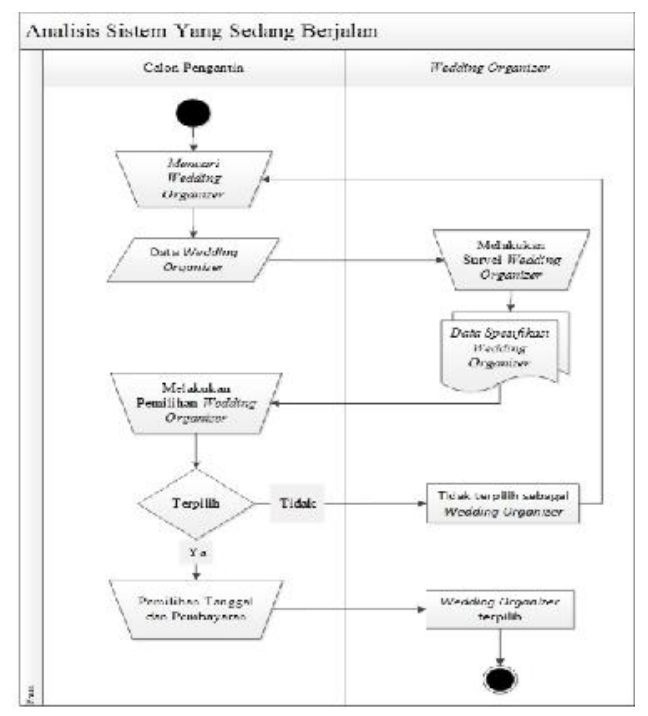

Gambar 3 Analisis Sistem Yang Sedang Berjalan

d) Analisis Sistem Yang Diusulkan

Merupakan proses kerja baru yang diusulkan berdasarkan hasil analisis sistem yang sedang berjalan, sehingga dihasilkan alur kerja baru yang sesuai dengan kebutuhan calon pengantin dalam rekomendasi pemilihan wedding organizer. Analisis sistem yang sedang diusulkan, ditunjukan pada gambar berikut. 


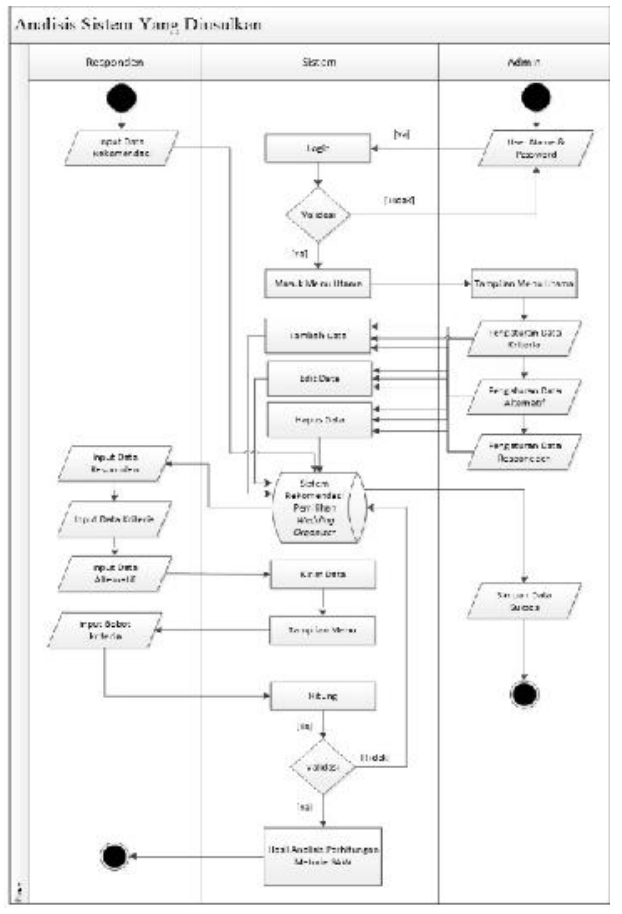

Gambar 4 Analisis Sistem Yang Sedang Diusulkan

e) Analisis Perhitungan Metode SAW Analisis perhitungan metode Simple Additive Weighting (SAW) dilakukan melalui tahapan perhitungan sebagai berikut :

1. Menentukan kriteria yang akan dijadikan acuan pengambilan keputusan yaitu $\mathrm{Ci}$. Untuk menentukan bobot dari masingmasing kriteria dibuat suatu prioritas atau tingkat kepentingan kriteria yang ditentukan oleh responden (calon pengantin). Dimana untuk menentukan bobot menggunakan skala prioritas. Berikut ini adalah skala prioritas tersebut :

1. $\quad$ Sangat Tidak Penting $(\mathrm{STP})=1$

2. Tidak Penting $(\mathrm{TP})=2$

3. Cukup Penting $(\mathrm{CP})=3$

4. Penting $(\mathrm{P})=4$

5. $\quad$ Sangat Penting $(\mathrm{SP})=5$

Kriteria dan prioritas yang ditentukan oleh responden (calon pengantin) dapat dilihat pada 1

Tabel 1 Data Kriteria dan Prioritas

\begin{tabular}{|c|c|c|c|c|}
\hline No & Kriteria & $\begin{array}{c}\text { Inisial } \\
\text { Kriteria }\end{array}$ & Atribut & Prioritas \\
\hline 1 & $\begin{array}{c}\text { Kelengkapan } \\
\text { Fasilitas }\end{array}$ & $\mathrm{C} 1$ & Benefit & Penting \\
\hline 2 & Populer & $\mathrm{C} 2$ & Benefit & $\begin{array}{c}\text { Cukup } \\
\text { Penting }\end{array}$ \\
\hline
\end{tabular}

\begin{tabular}{|c|c|c|c|c|}
\hline 3 & $\begin{array}{c}\text { Konsep } \\
\text { Dekorasi }\end{array}$ & C3 & Benefit & $\begin{array}{c}\text { Cukup } \\
\text { Penting }\end{array}$ \\
\hline 4 & Kualitas & C4 & Benefit & Penting \\
\hline 5 & Harga & C5 & Cost & $\begin{array}{c}\text { Sangat } \\
\text { Penting }\end{array}$ \\
\hline 6 & $\begin{array}{c}\text { Profesionalisme } \\
\text { WO }\end{array}$ & C6 & Cost & $\begin{array}{c}\text { Sangat } \\
\text { Penting }\end{array}$ \\
\hline
\end{tabular}

2. Menentukan rating kecocokan setiap alternatif pada setiap kriteria. Dari kriteria tersebut, maka dibuat suatu tingakatan kepentingan kriteria berdasarkan alternatif yang telah ditentukan kedalam nilai himpunan fuzzy. Ditahap ini responden (calon pengantin) mengisi bobot nilai dari setiap alternatif pada setiap kriteria yang telah ditentukan. Penentuan tabel nilai sub kriteria adalah sebagai berikut :

Tabel 2 Kelengkapan Fasilitas (C1)

\begin{tabular}{|c|c|c|c|c|}
\hline No & Nama Wedding Organizer & Inisial & $\begin{array}{c}\text { Total } \\
\text { Vendor }\end{array}$ & $\begin{array}{c}\text { Bobot } \\
\text { Nilai }\end{array}$ \\
\hline 1 & Sal Wedding & A1 & 6 & 2.5 \\
\hline 2 & Akbar Tenda Wedding & A2 & 16 & 10 \\
\hline 3 & $\begin{array}{c}\text { La Belle Wedding } \\
\text { Organizer }\end{array}$ & A3 & 11 & 5 \\
\hline 4 & $\begin{array}{c}\text { Warna Warni Event } \\
\text { W Wedding Organizer }\end{array}$ & A4 & 16 & 10 \\
\hline 5 & $\begin{array}{c}\text { Dwin Wedding } \\
\text { WeddingTree Wedding }\end{array}$ & A5 & 12 & 7.5 \\
\hline 6 & Organizer & 13 & 7.5 \\
\hline 8 & Our Jobs Production & A7 & 6 & 2.5 \\
\hline 9 & Lizza Wedding Organizer & A8 & 16 & 10 \\
\hline 10 & Kally Tenda wedding & A9 & 16 & 10 \\
\hline
\end{tabular}


Tabel 3 Populer (C2)

\begin{tabular}{|c|c|c|c|c|}
\hline No & $\begin{array}{c}\text { Nama Wedding } \\
\text { Organizer }\end{array}$ & Inisial & $\begin{array}{c}\text { Pengikut } \\
\text { Sosial } \\
\text { Media } \\
\end{array}$ & $\begin{array}{c}\text { Bobo } \\
t \\
\text { Nilai } \\
\end{array}$ \\
\hline 1 & Sal Wedding & A1 & 45.000 & 5 \\
\hline 2 & $\begin{array}{l}\text { Akbar Tenda } \\
\text { Wedding }\end{array}$ & A2 & 110.000 & 10 \\
\hline 3 & $\begin{array}{l}\text { La Belle } \\
\text { Wedding } \\
\text { Organizer }\end{array}$ & A3 & 80.000 & 7.5 \\
\hline 4 & $\begin{array}{l}\text { Warna Warni } \\
\text { Event } \\
\text { \& Wedding } \\
\text { Organizer }\end{array}$ & A4 & 45.000 & 5 \\
\hline 5 & Dwin Wedding & A5 & 46.000 & 5 \\
\hline 6 & $\begin{array}{c}\text { WeddingTree } \mathrm{W} \\
\text { edding } \\
\text { Organizer }\end{array}$ & A6 & 19.000 & 2.5 \\
\hline 7 & $\begin{array}{l}\text { Our Jobs } \\
\text { Production }\end{array}$ & A7 & 90.000 & 7.5 \\
\hline 8 & $\begin{array}{l}\text { Lizza Wedding } \\
\text { Organizer }\end{array}$ & A8 & 40.000 & 5 \\
\hline 9 & $\begin{array}{l}\text { Nelly Tenda } \\
\text { wedding }\end{array}$ & A9 & 110.000 & 10 \\
\hline 10 & $\begin{array}{l}\text { Kamadesta } \\
\text { Wedding }\end{array}$ & A10 & 90.000 & 7.5 \\
\hline
\end{tabular}

Tabel 4 Konsep Dekorasi (C3)

\begin{tabular}{|c|l|c|c|c|}
\hline No & $\begin{array}{l}\text { Nama Wedding } \\
\text { Organizer }\end{array}$ & Inisial & $\begin{array}{c}\text { Jumlah } \\
\text { Tema }\end{array}$ & $\begin{array}{c}\text { Bobot } \\
\text { Nilai }\end{array}$ \\
\hline 1 & Sal Wedding & A1 & 15 & 7.5 \\
\hline 2 & $\begin{array}{l}\text { Akbar Tenda } \\
\text { Wedding }\end{array}$ & A2 & 9 & 5 \\
\hline 3 & $\begin{array}{l}\text { La Belle } \\
\text { Wedding } \\
\text { Organizer }\end{array}$ & A3 & 14 & 7.5 \\
\hline 4 & $\begin{array}{l}\text { Warna Warni } \\
\text { Event \& } \\
\text { Wedding } \\
\text { Organizer }\end{array}$ & A4 & 15 & 7.5 \\
\hline 5 & Dwin Wedding & A5 & 8 & 5 \\
\hline 6 & $\begin{array}{l}\text { WeddingTree W } \\
\text { edding Organizer }\end{array}$ & A6 & 8 & 5 \\
\hline 7 & $\begin{array}{l}\text { Our Jobs } \\
\text { Production }\end{array}$ & A7 & 15 & 7.5 \\
\hline 8 & $\begin{array}{l}\text { Lizza Wedding } \\
\text { Organizer }\end{array}$ & A8 & 9 & 5 \\
\hline 9 & $\begin{array}{l}\text { Nelly Tenda } \\
\text { wedding }\end{array}$ & A9 & 18 & 7.5 \\
\hline 10 & $\begin{array}{l}\text { Kamadesta } \\
\text { Wedding }\end{array}$ & A10 & 9 & 5 \\
\hline
\end{tabular}

Tabel 5 Kualitas (C4)

\begin{tabular}{|c|l|c|c|c|}
\hline No & \multicolumn{1}{|c|}{$\begin{array}{c}\text { Nama } \\
\text { Wedding } \\
\text { Organizer }\end{array}$} & Inisial & Kualitas & $\begin{array}{c}\text { Bobot } \\
\text { Nilai }\end{array}$ \\
\hline 1 & Sal Wedding & A1 & Vip & 10 \\
\hline 2 & $\begin{array}{l}\text { Akbar Tenda } \\
\text { Wedding }\end{array}$ & A2 & Medium & 5 \\
\hline 3 & $\begin{array}{l}\text { La Belle } \\
\text { Wedding } \\
\text { Organizer }\end{array}$ & A3 & High Quality & 7.5 \\
\hline 4 & $\begin{array}{l}\text { Warna Warni } \\
\text { Event \& } \\
\text { Wedding } \\
\text { Organizer }\end{array}$ & A4 & High Quality & 7.5 \\
\hline 5 & $\begin{array}{l}\text { Dwin } \\
\text { Wedding }\end{array}$ & A5 & $\begin{array}{l}\text { Semi } \\
\text { Medium }\end{array}$ & 2.5 \\
\hline 6 & $\begin{array}{l}\text { WeddingTree } \\
\text { Wedding } \\
\text { Organizer }\end{array}$ & A6 & Medium & 5 \\
\hline 7 & $\begin{array}{l}\text { Our Jobs } \\
\text { Production }\end{array}$ & A7 & High Quality & 7.5 \\
\hline 8 & $\begin{array}{l}\text { Lizza } \\
\text { Wedding } \\
\text { Organizer }\end{array}$ & A8 & High Quality & 7.5 \\
\hline 9 & $\begin{array}{l}\text { Nelly Tenda } \\
\text { wedding }\end{array}$ & A9 & Vip & 10 \\
\hline 10 & $\begin{array}{l}\text { Kamadesta } \\
\text { Wedding }\end{array}$ & A10 & Medium & 5 \\
\hline
\end{tabular}

Tabel 6 Harga (C5)

\begin{tabular}{|c|l|c|c|c|}
\hline No & $\begin{array}{c}\text { Nama } \\
\text { Wedding } \\
\text { Organizer }\end{array}$ & Inisial & Harga & $\begin{array}{c}\text { Bobot } \\
\text { Nilai }\end{array}$ \\
\hline 1 & Sal Wedding & A1 & $\begin{array}{c}\text { Rp. } \\
65.000 .000\end{array}$ & 5 \\
\hline 2 & $\begin{array}{l}\text { Akbar Tenda } \\
\text { Wedding }\end{array}$ & A2 & $\begin{array}{c}\text { Rp. } \\
18.000 .000\end{array}$ & 0.5 \\
\hline 3 & $\begin{array}{l}\text { La Belle } \\
\text { Wedding } \\
\text { Organizer }\end{array}$ & A3 & $\begin{array}{c}\text { Rp. } \\
60.000 .000\end{array}$ & 5 \\
\hline 4 & $\begin{array}{l}\text { Warna } \\
\text { Warni Event } \\
\text { \& Wedding } \\
\text { Organizer }\end{array}$ & A4 & $\begin{array}{c}\text { Rp. } \\
60.000 .000\end{array}$ & 5 \\
\hline 6 & $\begin{array}{l}\text { WeddingTre } \\
\text { e Wedding } \\
\text { Organizer }\end{array}$ & A6 & $\begin{array}{c}\text { Rp. } \\
40.000 .000\end{array}$ & 2.5 \\
\hline 7 & $\begin{array}{l}\text { Our Jobs } \\
\text { Production }\end{array}$ & A7 & $\begin{array}{c}\text { Rp. } \\
60.000 .000\end{array}$ & 5 \\
\hline 8 & $\begin{array}{l}\text { Lizza } \\
\text { Wedding } \\
\text { Organizer }\end{array}$ & A8 & $\begin{array}{c}\text { Rp. } \\
40.000 .000\end{array}$ & 2.5 \\
\hline 9 & $\begin{array}{l}\text { Nelly Tenda } \\
\text { wedding }\end{array}$ & A9 & $\begin{array}{c}\text { Rp. } \\
40.000 .000\end{array}$ & 2.5 \\
\hline 10 & $\begin{array}{l}\text { Kamadesta } \\
\text { Wedding }\end{array}$ & A10 & $\begin{array}{c}\text { Rp. } \\
45.000 .000\end{array}$ & 2.5 \\
\hline
\end{tabular}


Tabel 7 Profesionalisme WO (C5)

\begin{tabular}{|c|c|c|c|c|}
\hline No & $\begin{array}{c}\text { Nama Wedding } \\
\text { Organizer }\end{array}$ & Inisial & $\begin{array}{c}\text { Waktu } \\
\text { Pekerjaan }\end{array}$ & $\begin{array}{l}\text { Bobot } \\
\text { Nilai }\end{array}$ \\
\hline 1 & Sal Wedding & A1 & 3 & 2.5 \\
\hline 2 & $\begin{array}{l}\text { Akbar Tenda } \\
\text { Wedding }\end{array}$ & A2 & 2 & 0.5 \\
\hline 3 & $\begin{array}{c}\text { La Belle } \\
\text { Wedding } \\
\text { Organizer }\end{array}$ & A3 & 2 & 0.5 \\
\hline 4 & $\begin{array}{l}\text { Warna Warni } \\
\text { Event \& } \\
\text { Wedding } \\
\text { Organizer }\end{array}$ & A4 & 3 & 2.5 \\
\hline 5 & Dwin Wedding & A5 & 4 & 5 \\
\hline 6 & $\begin{array}{l}\text { WeddingTree We } \\
\text { dding Organizer }\end{array}$ & A6 & 3 & 2.5 \\
\hline 7 & $\begin{array}{l}\text { Our Jobs } \\
\text { Production }\end{array}$ & A7 & 2 & 0.5 \\
\hline 8 & $\begin{array}{c}\text { Lizza Wedding } \\
\text { Organizer }\end{array}$ & A8 & 2 & 0.5 \\
\hline 9 & $\begin{array}{l}\text { Nelly Tenda } \\
\text { wedding }\end{array}$ & A9 & 3 & 2.5 \\
\hline 10 & $\begin{array}{l}\text { Kamadesta } \\
\text { Wedding }\end{array}$ & A10 & 3 & 2.5 \\
\hline
\end{tabular}

3. Membuat matriks keputusan $X$ berdasarkan kriteria (Ci) yang dibentuk berdasarkan rating alternatif.

Matriks Rating Kecocokan

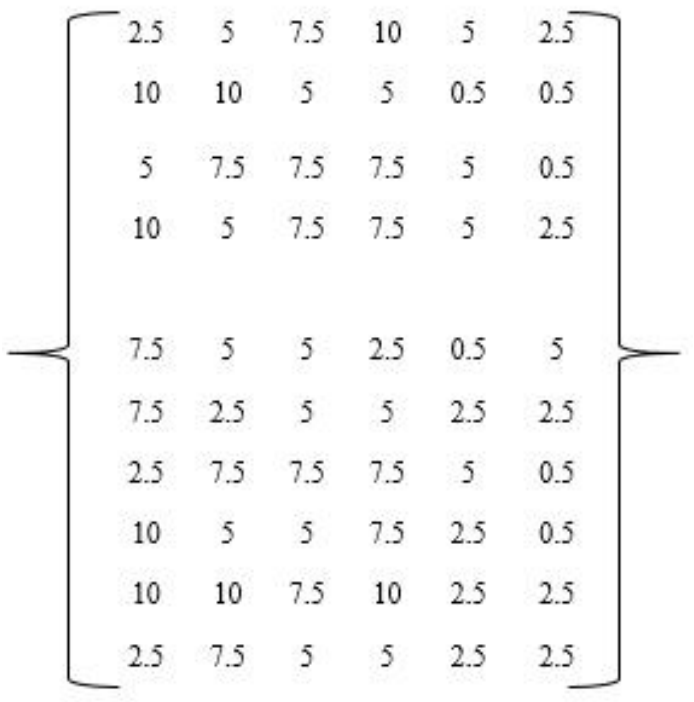

4. Membuat normalisasi Matriks $X$ dengan menggunakan Rumus Persamaan (1)

Hasil dari nilai rating kinerja ternormalisasi $\left(r_{i j}\right)$ dengan menggunakan rumus pada persamaan (1) akan membentuk matriks ternormalisasi $(\mathbf{R})$.
Adapun matriks ternormalisasi $\mathbf{R}$ adalah sebagai berikut :

Matriks R

$\left[\begin{array}{cccccc}0.25 & 0.5 & 1 & 1 & 10 & 5 \\ 1 & 1 & 0.67 & 0.5 & 1 & 1 \\ 0.5 & 0.75 & 1 & 0.75 & 10 & 1 \\ 1 & 0.5 & 1 & 0.75 & 10 & 5 \\ 0.75 & 0.5 & 0.67 & 0.25 & 1 & 10 \\ 0.75 & 0.25 & 0.67 & 0.5 & 5 & 5 \\ 0.25 & 0.75 & 1 & 0.75 & 10 & 1 \\ 1 & 0.5 & 0.67 & 0.75 & 5 & 1 \\ 1 & 1 & 1 & 1 & 5 & 5 \\ 0.25 & 0.75 & 0.67 & 0.5 & 5 & 5 \\ & & & & & \end{array}\right]$

5. Melakukan Proses perangkingan dengan menggunakan rumus persamaan (2).

Proses perkalian pada peranngkingan ini menggunakan data kriteria bobot tingkat

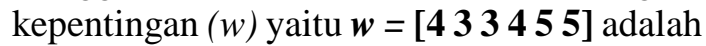
sebagai berikut :

$$
\begin{aligned}
& \text { V1 }:(4 * 0.25)+(3 * 0.5)+(3 * 1)+(4 * 1)+ \\
& (5 * 10)+(5 * 5)=84.6 \\
& \text { V2: }(4 * 1)+(3 * 1)+(3 * 0.67)+(4 * 0.5)+ \\
& \left(5^{*} 1\right)+\left(5^{*} 1\right)=21.0 \\
& \text { V3 : }(4 * 0.5)+(3 * 0.75)+(3 * 1)+(4 * 0.75) \\
& +(5 * 10)+(5 * 1)=65.3 \\
& \text { V4 : }(4 * 1)+(3 * 0.5)+(3 * 1)+(4 * 0.75)+ \\
& (5 * 10)+(5 * 5)=86.5 \\
& \text { V5 : }(4 * 0.75)+(3 * 0.5)+(3 * 0.67)+ \\
& (4 * 0.25)+(5 * 1)+(5 * 10)=62.5 \\
& \text { V6 : }(4 * 0.75)+(3 * 0.25)+(3 * 0.67)+ \\
& (4 * 0.5)+(5 * 5)+(5 * 5)=57.8 \\
& \text { V7 }:(4 * 0.25)+(3 * 0.75)+(3 * 1)+(4 * 0.75) \\
& +(5 * 10)+(5 * 1)=64.3 \\
& \text { V8 : }(4 * 1)+(3 * 0.5)+(3 * 0.67)+(4 * 0.75) \\
& +(5 * 5)+(5 * 1)=40.5 \\
& \text { V9: }(4 * 1)+(3 * 1)+(3 * 1)+(4 * 1)+(5 * 5) \\
& +(5 * 5)=64.0
\end{aligned}
$$


V10 : $(4 * 0.25)+(3 * 0.75)+(3 * 0.67)+$ $(4 * 0.5)+(5 * 5)+(5 * 5)=57.3$

Hasil perhitungan dari tahapan persamaan (1) hingga persamaan (2) dapat dilihat pada tabel 8 sebagai berikut :

Tabel 8 Hasil Pemilihan Weddig Organizer

\begin{tabular}{|c|c|l|c|c|}
\hline Inisial & Ranking & \multicolumn{1}{|c}{ Alternatif } & Rating & $\begin{array}{c}\text { Rating } \\
\%\end{array}$ \\
\hline A4 & 1 & $\begin{array}{l}\text { Warna Warni Event \& } \\
\text { Wedding Organizer }\end{array}$ & 86.5 & 14.33 \\
\hline A1 & 2 & Sal Wedding & 84.6 & 14.01 \\
\hline A3 & 3 & $\begin{array}{l}\text { La Belle Wedding } \\
\text { Organizer }\end{array}$ & 65.3 & 10.82 \\
\hline A7 & 4 & Our Jobs Production & 64.3 & 10.65 \\
\hline A9 & 5 & Nelly Tenda wedding & 64.0 & 10.60 \\
\hline A5 & 6 & Dwin Wedding & 62.5 & 10.35 \\
\hline A6 & 7 & $\begin{array}{l}\text { WeddingTree Wedding } \\
\text { Organizer }\end{array}$ & 57.8 & 9.58 \\
\hline A10 & 8 & Kamadesta Wedding & 57.3 & 9.49 \\
\hline A8 & 9 & $\begin{array}{l}\text { Lizza Wedding } \\
\text { Organizer }\end{array}$ & 40.5 & 6.71 \\
\hline A2 & 10 & Akbar Tenda Wedding & 21.0 & 3.48 \\
\hline & & TOTAL & 603.65 & 100 \\
\hline
\end{tabular}

3.2 Desain

Tahap desain sistem dilakukan dengan pendekatan object oriented Programming (OOP) yang digambarkan melalui unified modelling language (UML). Adapun diagram UML yang digunakan meliputi use case diagram, activity diagram, sequence diagram, class diagram dan deployment diagram. Selain itu, pada tahap ini juga dilakukan desain database dan desain interface.

\subsection{Pengkodean (Coding)}

Pada tahap ini, hasil desain diimplementasikan melalui pemrograman berorientasi objek menggunakan bahasa pemrograman PHP. Selain itu, pada tahap ini dilakukan penerapan metode simple additive weighting (SAW) diterapkan ke dalam unit program.

\subsection{Pengujian Sistem}

Pada tahap ini dilakukan pengujian sistem menggunakan metode blackbox untuk memastikan bahwa input yang digunakan menghasilkan output yang sesuai
1) Halaman Login

Halaman login merupakan tampilan awal ketika user akan menggunakan sistem, pada tampilan login ini userdiharuskan untuk menginputkan username dan password untuk dapat mengakses sistem. Berikut tampilan halaman login ditunjukkan pada gambar dibawah.

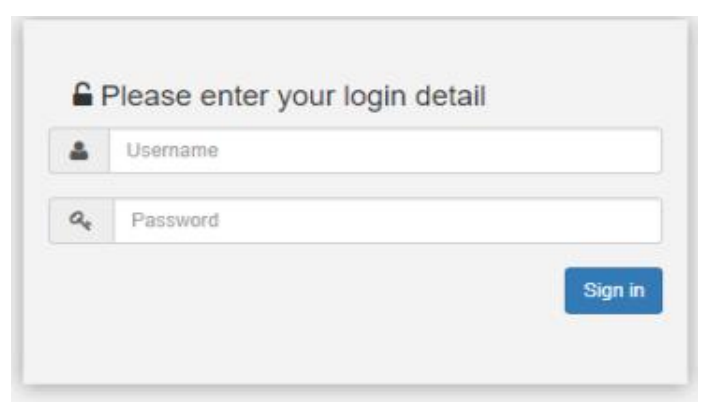

Gambar 5 Halaman Login

2) Halaman Beranda

Pada halaman beranda ini merupakan tampilan utama untuk responden (calon pengantin) memulai analisis pemilihan wedding organizer.

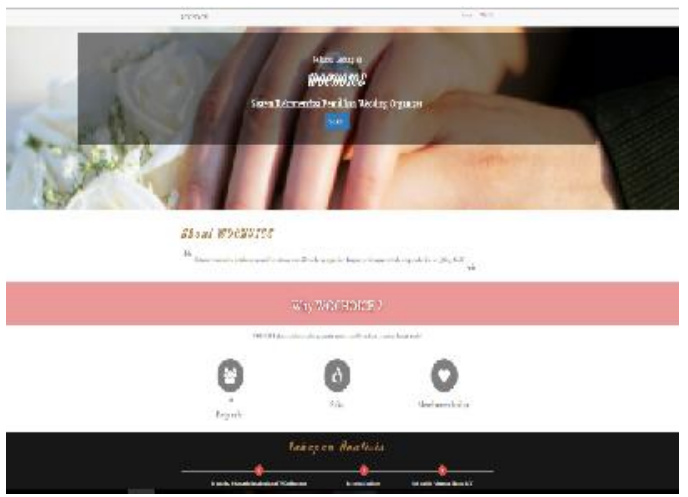

Gambar 6 Halaman Beranda

3) Halaman Pengaturan Data Kriteria

Halaman pengaturan data kriteria merupakan tampilan menu kriteria yang dapat diakses oleh admin. Dalam menu ini admin dapat mengubah, menambah, ataupun menghapus data pada history kriteria. 


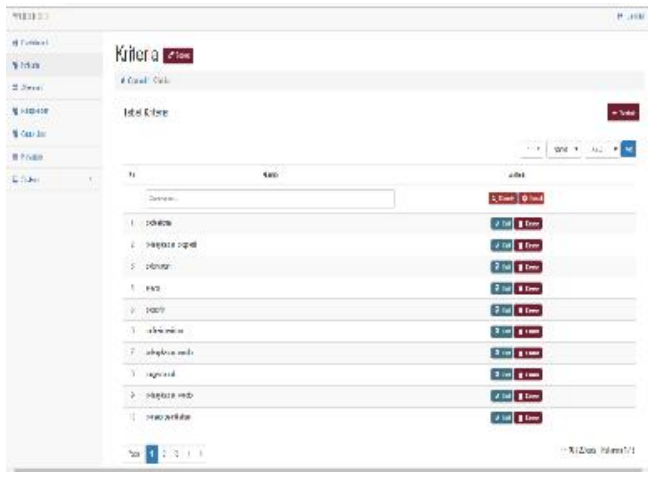

Gambar 7 Pengaturan Data kriteria 4) Halaman Pengaturan Data Alternatif

Halaman pengaturan data alternatif merupakan tampilan menu alternatif yang dapat diakses oleh admin. Dalam menu ini admin dapat mengubah, menambah, ataupun menghapus data pada history alternatif.

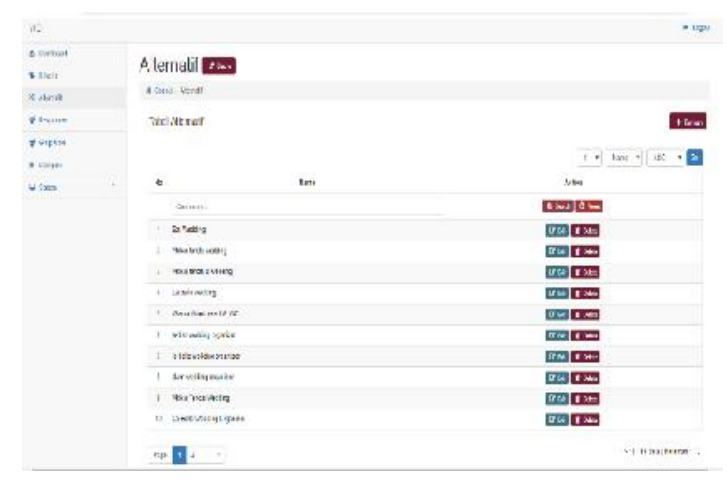

Gambar 8 Pengaturan Data Alternatif

5) Halaman Pengaturan Data Responden

Halaman pengaturan data responden merupakan tampilan menu responden yang dapat diakses oleh admin, dalam menu ini admin dapat mengubah, menambah, ataupun menghapus data pada history responden

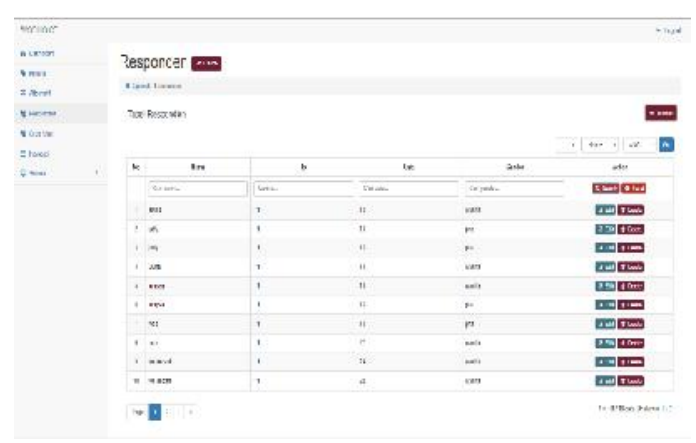

Gambar 9 Pengaturan Data Responden
6) Halaman Input Data Rekomendasi

Halaman input data rekomendasi merupakan tampilan untuk responden (calon pengantin) input data rekomendasi. Dalam step ini berisikan input data responden, input data kriteria, dan input data alternative

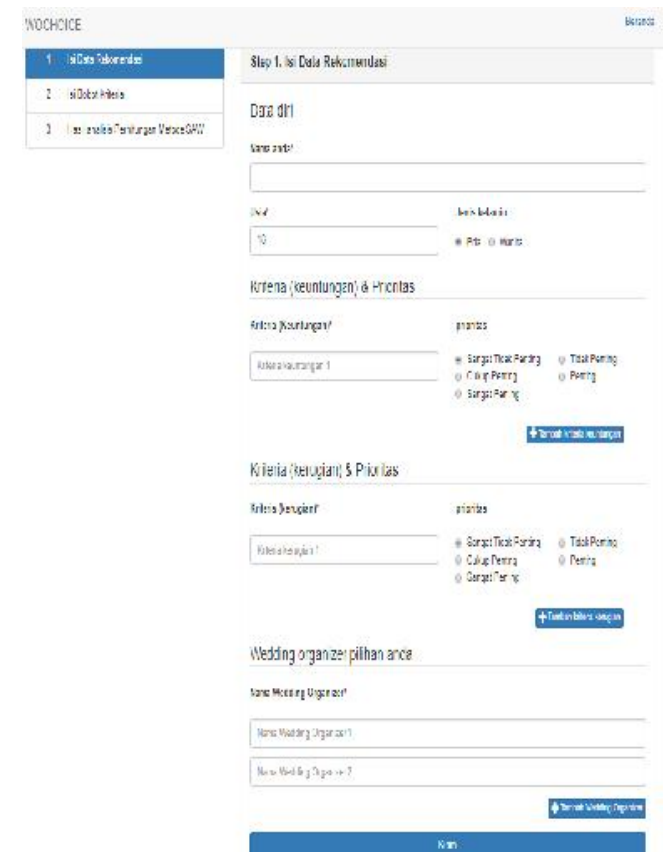

Gambar 10 Input Data Rekomendasi

7) Halaman Input Bobot Kriteria

Halaman input bobot kriteria merupakan tampilan untuk responden melanjutkan analisis pemilihan wedding organizer dengan mengisikan bobot kriteria pada setiap alternatif..

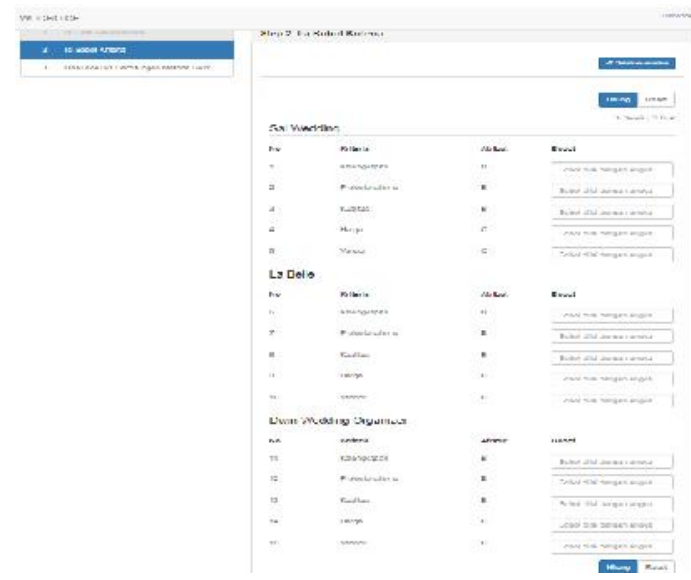

Gambar 11 Input Bobot Kriteria 
8) Halaman Hasil Analisis Perhitungan SAW Halaman hasil analisis perhitungan SAW merupakan tampilan hasil perhitungan analisis pemilihan wedding organizer dengan metode simple additive weighting (SAW).

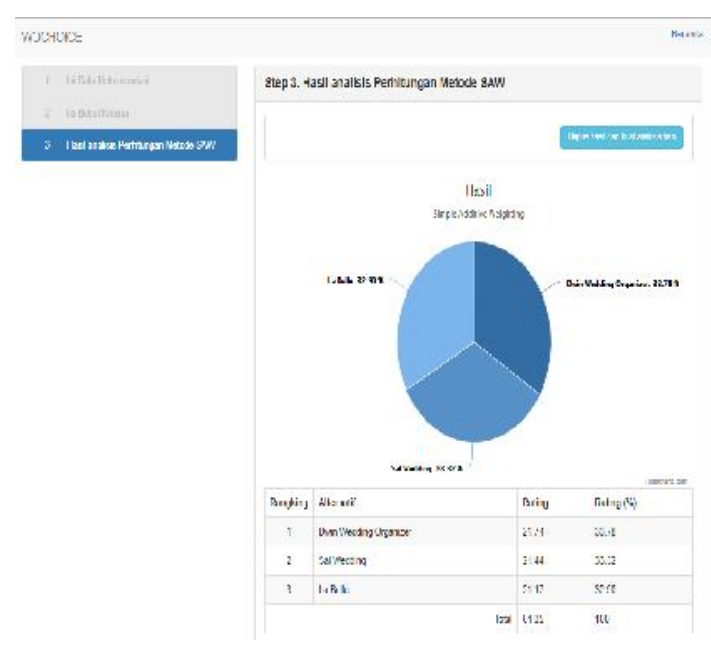

Gambar 12 Hasil Analisis Perhitungan SAW

\section{KESIMPULAN}

Berdasarkan uraian dan pembahasan diatas, maka dapat ditarik kesimpulan sebagai berikut.

1. Hasil dari analisis pemilihan Wedding Organizer dengan penerapan perhitungan metode Simple Additive Weighting (SAW) berdasarkan tahapan perhitungan persamaan ke (1) hingga persamaan ke (2), didapatkan hasil rekomendasi Wedding Organizer terpilih adalah alternatif (A4) yaitu Warna Warni Event \& Wedding Organizer. Merupakan wedding organizer yang direkomendasi sebagai Wedding Organizer terbaik dengan nilai tertinggi yaitu 86.5.

2. Perancangan sistem rekomendasi pemilihan Wedding Organizer dengan model UML dihasilkan : Use Case Diagram, Activity Diagram, Sequence Diagram, Class Diagram, Deployment Diagram, desain Database dan desain Interface.

\section{UCAPAN TERIMA KASIH}

Penulis mengucapkan terima kasih kepada Ibu Novita Br. Ginting S.kom., M.Kom dan Ibu Dewi Primasari S.Si, M.M yang telah memberi bimbingan dalam penulisan penelitian ini.

\section{DAFTAR PUSTAKA}

[1] S,Kusumadewi,S.Hartati, A.Harjoko dan R.Wardoyo., Fuzzy Multi Attribute Decision Making (FUZZY $M A D M)$. Yogyakarta: Graha Ilmu.2006.

[2] Darmastuti,Destriyana.Implementasi metode simple additive weighting (SAW) dalam sistem informasi lowongan kerja berbasis web untuk rekomendasi pencari kerja terbaik, jurnal ilmiah Teknik Informatika, 2013.

[3] Pressman RS. Software Engineering : A Practitioner's Approach (edisi kelima). USA: McGraw-Hill. 2001. 